\title{
O CABO E A REDE: RELAÇÕES ENTRE A NOVA LEI DA TV PAGA E A PRODUÇÃO DE WEBSÉRIES BRASILEIRAS
}

\author{
The cable and the net: relations between the new pay tv law and the productions \\ of Brazilian webseries
El cable y la red: relaciones entre la nueva ley de tv paga y la producción de webséries brasileñas

Clarice Greco

Professora do Programa de Pós-graduação em Comunicação da Universidade Paulista

(UNIP).claricegreco@gmail.com

Tomaz Penner

Doutorando no Programa de Pós-graduação em Ciências da Comunicação na Escola e Comunicações e Artes da Universidade de São Paulo (ECA-USP). tomazpenner@gmail.com

\section{Resumo}

O trabalho traça um panorama da implantação da Lei 12.485, conhecida também como lei da TV paga ou lei do cabo, que regulamenta cotas para produção nacional na TV por assinatura. $\mathrm{O}$ surgimento e fortalecimento de produções nacionais gera um cenário propício à experimentação de formatos e ao estímulo da indústria criativa. Por meio de um estudo exploratório, foram analisadas obras ficcionais desde 2011 exibidas na TV paga que tenham surgido como webséries. O objetivo é investigar as relações entre o processo de implementação da lei do cabo, as produtoras independentes e a popularização do formato websérie. Como resultado principal, verificou-se que é possível correlacionar o aquecimento do mercado de produção audiovisual para a internet com a implementação da lei do cabo, visto que algumas ficções exibidas na TV têm a internet como fonte de conteúdos.

Palavras-chave: Lei do cabo. Webséries. TV paga.

\begin{abstract}
The work traces a panorama of the implementation of the Law 12.485, also known as pay-TV law or cable law, which regulates quotas for national production in pay-TV. The emergence and strengthening of national productions creates a favorable scenario to the experimentation of formats and the stimulation of the creative industry. Through an exploratory study, we have analyzed fictional productions created as webseries and also aired or adapted by pay TV since 2011. The goal is to investigate the relations between the process of implementing the law, the independent producers and the popularization of webseries. As a main result, we verified that it is possible to correlate the heating of the audiovisual industry with the implementation of the cable law, since some fictions shown on TV have the Internet as source of contents.
\end{abstract}


Key words: Pay TV law. Webseries. TV fiction.

\section{Resumen}

El trabajo traza un panorama de la implantación de la Ley 12.485, conocida también como la nueva ley de la TV de pago o ley del cable, que regula cuotas para producción nacional en la TV por suscripción. El surgimiento y fortalecimiento de producciones nacionales genera un escenario propicio a la experimentación de formatos y al estímulo de la industria creativa. Por medio de un estudio exploratorio, se analizaron obras de ficción exhibidas desde 2011 en la TV de pago que surgieron también como webseries. El objetivo es investigar las relaciones entre el proceso de implementación de la ley del cable, las productoras independientes y la popularización del formato webserie. Como resultado, se verificó que es posible correlacionar el calentamiento del mercado de producción audiovisual para Internet con la implementación de la ley del cable, ya que algunas ficciones exhibidas en la TV tienen la Internet como fuente de contenidos.

Palabras clave: TV de pago. Webseries. Ficción televisiva.

\section{INTRODUÇÃO}

A produção audiovisual de um país não pode ser compreendida como apenas expressão cultural, ou, por outro lado, enquanto simples produção mercadológica. É, na verdade, uma simbiose entre ambos, principalmente quando se leva em conta o Brasil, onde as ficções televisivas podem estabelecer uma narrativa sobre a nação (Lopes, 2003) mesmo que sejam produzidas, de maneira vertical, sob a lógica de grandes corporações e com ampla aceitação no cenário internacional, como ocorre com as telenovelas.

$\mathrm{Na}$ pesquisa aqui relatada, concentramos esforços especialmente nas produções ficcionais. O recorte se justifica pelo reconhecimento da ficção como o maior expoente cultural da produção televisiva brasileira. No entanto, nosso foco de interesse são as possíveis correlações entre as séries de TV derivadas de produção para internet, e a implementação da Lei 12.485, conhecida como lei do cabo. Buscamos entender a influência da norma sobre o mercado de webséries brasileiras. Por mais que ela não regule oficialmente a produção de conteúdo para a internet, nossa hipótese é de que as cotas nacionais propostas pela lei estimulam também as ficções online. Visamos ainda compreender o lugar das produtoras independentes nesse contexto e como elas se desenvolveram nos últimos anos, desde a implementação dessas medidas.

A princípio, discutimos aspectos do atual cenário midiático brasileiro e de que maneira a lei do cabo regulamenta a produção para a TV paga brasileira. Também são feitas reflexões sobre a realização independente e a produção em multiplataformas. Por fim, apresentamos a 
metodologia de seleção do nosso corpus e partimos para as análises de produções audiovisuais de ficção que transitaram entre os formatos websérie e série televisiva.

\section{Políticas De PROTECIONismo CULTURAL E A LEI DO CABO BRASILEIRA}

É possível desenhar o cenário de realização audiovisual brasileiro como palco de disputas e conflitos, no qual produções de baixo orçamento competem com as de grandes veículos de comunicação e títulos internacionais ganham espaço nas grades horárias, muitas vezes em detrimento do conteúdo local. Nesse contexto televisivo e cinematográfico internacionalizado e dominado em parte pelos produtos estadunidenses, medidas de protecionismo da produção cultural nacional são comuns ao redor do mundo. Existem várias maneiras de "privilegiar" a realização local, que vão desde o investimento em emissoras públicas até a exigência de transmissão de tipos específicos de conteúdos - que podem determinar, entre outras características, a sua nacionalidade. Esse dispositivo é conhecido como "cota de tela", e é relativamente usual no cenário internacional, sendo adotado, por exemplo, na Coreia, Espanha e Itália e compreendido desde 1947 - pelo General Agreement on Tariffs and Trade ${ }^{1}$ (GATT) - como uma medida legítima de políticas culturais nacionais.

A resolução do GATT gerou polêmica no cenário internacional à época de sua implantação e jamais foi aceita pelos Estados Unidos, que a consideravam como um atentado à liberdade de expressão e circulação de informações. Do outro lado, países europeus defendiam a medida como legítima, alegando que protegiam suas realizações do ostracismo e da consequente extinção em nome de uma massificação cultural liderada pelos EUA.

Após muita disputa, em 2005 a UNESCO aprovou uma convenção sobre Proteção e Promoção da Diversidade das Expressões Culturais, que passou a assumir a regulamentação desse tópico. Apesar de a convenção não cessar as polêmicas e discussões, ela passou a legitimar medidas de proteção de produções culturais nacionais e embasou o estabelecimento, no caso brasileiro, da lei de cotas de tela para a TV por assinatura.

Existem, é claro, implicações históricas no cenário vivido hoje pela televisão brasileira, já que a escolha do modelo televisivo de um país é sempre resultado de uma série

\footnotetext{
${ }^{1}$ O General Agreement on Tariffs and Trade (ou Acordo Geral de Tarifas e Comércio em português) foi um tratado assinado por 23 países fundadores, que buscou regulamentar as relações comerciais internacionais. $\mathrm{O}$ Acordo está na base da criação da Organização Mundial do Comércio e compreende as produções audiovisuais a partir de seu entendimento como um híbrido entre aspectos econômicos e culturais, conforme explicado anteriormente.
} 
de razões culturais, políticas e técnicas. Desde que foi estabelecida no Brasil, na década de 1950, o Estado influenciou de várias maneiras nessa indústria, entre elas ao estimular o modelo comercial em detrimento de experiências consistentes de televisão pública no país. Junte-se a isso a era dos satélites Brasilsat a partir de 1985, que complementaram a técnica de reprodução ao vivo fazendo com que todas as regiões brasileiras fossem alcançadas. Surgem assim as redes nacionais com sistema de filiação de redes regionais a grandes emissoras, o que reduziu o número de canais e redes de TV, concentrando-as no sudeste por deter o capital financeiro e o poder político. Com os avanços conquistados, a Rede Globo se tornou hegemônica entre os canais de TV aberta com cobertura nacional, enquanto as pequenas emissoras deveriam escolher entre a filiação a uma grande rede, ou a falência.

Trocando em miúdos, isso representa uma conjuntura desfavorável à realização independente, que, além de lidar com a falta de recursos, se vê impossibilitada de "escoar" suas produções no mercado televisivo nacional, devido ao seu alto nível de concentração, aliado a um sistema de produção dos canais abertos que privilegia a construção de uma grade horária com produções ficcionais próprias. Porém, uma esperança despontou no horizonte quando, na década de 1990, a TV paga surgiu no Brasil ${ }^{2}$. Apesar de o marco legal que regulamentou seu estabelecimento definir apenas a obrigatoriedade de uma emissora brasileira compor a oferta da grade de canais, a TV paga surgiu como possibilidade de oportunidade aos produtores independentes, que em 1999 se organizaram e criaram a Associação Brasileira de Produtores Independentes (ABPI-TV).

Organizados nessa associação, os produtores passaram a exigir medidas de proteção aos conteúdos domésticos, o que possibilitou, nos anos 2000, que pela primeira vez na história brasileira os conteúdos televisivos também passassem a ser contemplados nas políticas nacionais audiovisuais, visto que, até então, somente o cinema era levado em conta nesse âmbito. Esse contexto permitiu, além da organização dos produtores independentes, que fossem abertos precedentes para se pensar em políticas públicas dos conteúdos televisivos nacionais.

Em 2004, o Ministério da Cultura apresentou o projeto de criação da Agência Nacional do Cinema e do Audiovisual (Ancinav), que regularia a $\mathrm{TV}$, e não mais apenas o cinema, e criava regras relativas ao conteúdo

\footnotetext{
${ }^{2}$ Inicialmente tímida, a TV paga no Brasil alcançou, em 2014, quase 20 milhões de usuários. Dados: ANCINE (Agência Nacional do Cinema). Disponível em: http://oca.ancine.gov.br/media/SAM/2014/Programacao/Informe_TvPaga_2014_versaopublicacao_0608.pdf. Acesso em julho de 2016.
} 
televiso e à proteção contra Hollywood. Acusado de interferir em negócios privados e quebrar regras comerciais, o projeto foi arquivado pelo presidente Lula em 2005. (SOUSA, 2014, p. 7).

Esse panorama permitiu que, em 2007, fosse colocado em discussão o Projeto de Lei 116 - que deu origem à Lei 12.485, que vigora hoje. Conhecida como "lei do cabo" ou "lei da TV paga"- a despeito de contemplar operadoras de TV paga via cabo, satélite ou fibra ótica -, a norma foi publicada no Diário Oficial em setembro de 2011 e tem três grandes focos de atuação: a) permitir que as corporações de telecomunicações possam oferecer o serviço de TV paga, como maneira de aumentar a concorrência e diminuir o valor do serviço cobrado ao consumidor; b) estabelecer, progressivamente, que a cada três canais estrangeiros ofertados nos pacotes assinados, um seja nacional; e c) estipular um aumento gradativo da obrigatoriedade de exibição de conteúdos nacionais nas emissoras ${ }^{3}$, de modo que, atualmente, um em cada três canais componentes do pacote de assinaturas deve ser nacional

Vale ressaltar que essa obrigatoriedade recai aos canais qualificados, que são definidos como emissoras que exibem prioritariamente filmes, séries, animações e documentários. De acordo com o capítulo 4 da Instrução Normativa 100 da Agência Nacional do Cinema (ANCINE), os espaços qualificados são o "espaço total do canal de programação, excluindose conteúdos religiosos ou políticos, manifestações e eventos esportivos, concursos, publicidade, televendas, infomerciais, jogos eletrônicos, propaganda política obrigatória, conteúdo audiovisual veiculado em horário eleitoral gratuito, conteúdos jornalísticos e programas de auditório ancorados por apresentador"4. Além disso, a norma também se direciona às produtoras independentes, que devem ser responsáveis pela produção de pelo menos metade dos conteúdos exibidos no montante de espaços do horário nobre contemplados pela lei do cabo. Desse modo, é possibilitado às produtoras independentes que tenham obrigatoriamente suas produções veiculadas no prime time de espaços qualificados da TV paga. São essas produtoras, inclusive, que, ao ganharem força e espaço no mercado,

\footnotetext{
${ }^{3} \mathrm{O}$ aumento gradativo seguiu o seguinte modelo: ano 1 (2011): os canais deveriam exibir uma hora e dez minutos de programação nacional no horário nobre ${ }^{3}$ semanalmente, sendo metade dela realizada por produtoras independentes. Aqui, um em cada nove canais ofertados nos pacotes de TV paga deveria ser nacional. Ano 2 (2012): os canais deveriam exibir duas horas e vinte minutos de programação nacional no horário nobre semanalmente, sendo metade dela realizada por produtoras independentes. Assim, um em cada seis canais ofertados nos pacotes de TV paga deve ser nacional. Ano 3 (2013): a partir de então, os canais devem exibir três horas e trinta minutos de programação nacional no horário nobre semanalmente, sendo metade dela realizada por produtoras independentes. Aqui, finalmente, um em cada três canais componentes do pacote de assinaturas deve ser nacional

${ }^{4}$ Fonte: INSTRUÇÃO NORMATIVA (ANCINE) n ${ }^{\circ}$ 100, de 29 de maio de 2012.
} 
investem também na inovação de formatos no ambiente multiplataforma, como no caso das webséries, sobre as quais trataremos adiante

\section{A PRODUÇÃO INDEPENDENTE BRASILEIRA E A CONVERGÊNCIA DE CONTEÚDOS}

Dentro desse contexto, é importante definir do que se fala na exigência de que metade do conteúdo seja realizada por produtoras independentes. Quais são essas produtoras? Segundo a lei 12.485 , são contempladas sob essa categoria as produtoras que: a) não são controladoras, controladas ou coligadas a programadoras, empacotadoras, distribuidoras ou concessionárias de serviço de radiodifusão de sons e imagens; b) não estão vinculadas a instrumentos que, direta ou indiretamente, confiram ou visem conferir a sócios minoritários, quando estes forem programadoras, empacotadoras, distribuidoras ou concessionárias de serviços de radiodifusão de sons e imagens, direito de veto comercial ou qualquer tipo de interferência comercial sobre os conteúdos produzidos; c) não mantêm vínculos de exclusividade que as impeçam de produzir ou comercializar para terceiros os conteúdos audiovisuais por elas produzidos 5 .

Percebe-se, portanto, que as medidas, além de priorizarem a programação nacional, estimulam o surgimento e crescimento de produções independentes de realizadores que sempre estiveram fora do oligopólio de mídia estabelecido historicamente no Brasil. De acordo com Marco Altberg, presidente da ABPI-TV, a configuração do novo cenário ocorre como um desenvolvimento natural do mercado audiovisual brasileiro ${ }^{6}$. O impacto pode ser observado pelo Gráfico 1, a seguir, que mostra o crescimento do número de produtoras associadas entre os anos de 2011 e 2014.

\footnotetext{
${ }^{5}$ Fonte: ANCINE - http://www.ancine.gov.br/faq-lei-da-tv-paga. Acesso em julho de 2016.

6 “ABPI-TV atinge a marca de 400 associados". Fonte: site ABPI-TV - 


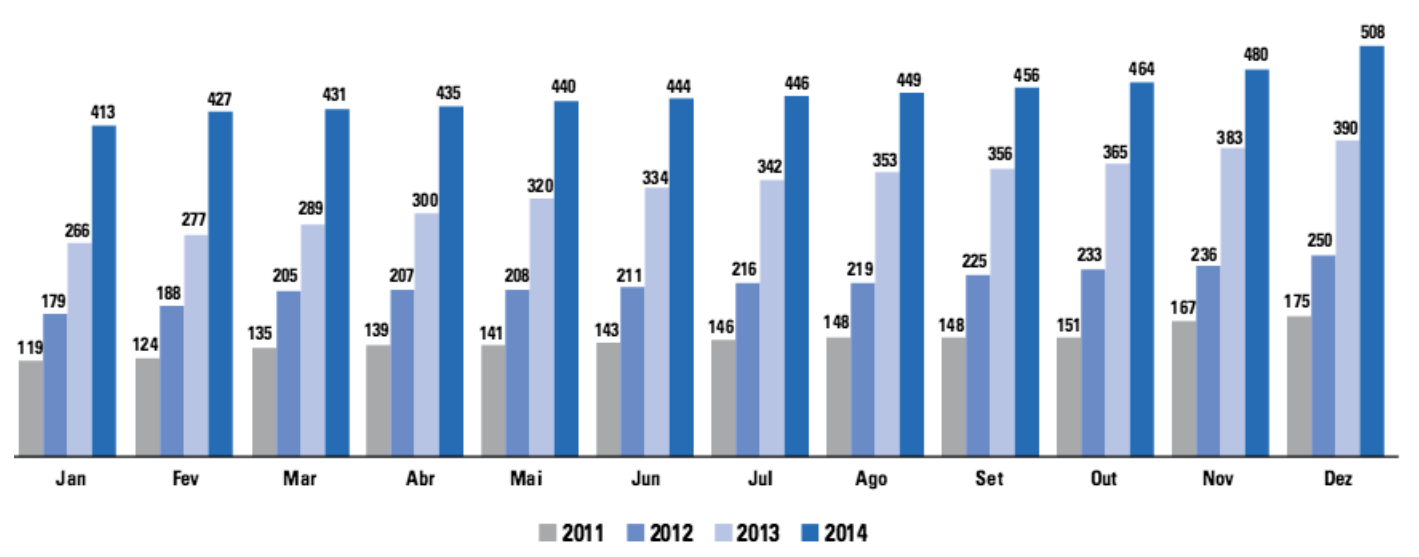

Fonte: Anuário ABPI-TV 2014.

Com base nesses dados, é possível verificar o crescimento expressivo de produtoras independentes entre os anos de 2011 e 2014, o que resulta na diversidade de obras e vozes compondo o cenário midiático nacional nesse período. Apesar de a normatização se dirigir especificamente aos conteúdos televisivos, não é possível deixar de considerar o contexto de realização multiplataforma no qual as produtoras beneficiadas pelas cotas de tela certamente criam para outros ambientes além da TV.

Para a maior parte da população brasileira, que ainda concentra na televisão sua principal fonte de informação e entretenimento, a lei do cabo cumpre sua função de democratização do mercado e estímulo à produção nacional. Todavia, não é possível ignorar que há um nicho de realização audiovisual que cresce à revelia de normas como essa, no território "livre" da internet - buscando seu financiamento e espaço nas redes. O que se percebe, no entanto, é que o fortalecimento das produtoras independentes por meio da Lei da TV paga, por mais que normativamente tenha abrangência exclusivamente televisiva, acaba interferindo colateralmente na quantidade e qualidade das realizações destinadas à internet. Mais do que isso, a lei acaba por incentivar também a renovação da grade televisiva a partir de conteúdos lançados online, como no caso das produções televisivas derivadas de webséries.

Segundo Jenkins (2008, p. 311), vivemos "um momento de transição, no qual antigas regras estão abertas a mudanças" e dependem de uma complexa negociação que envolve tensões entre modelos de produção, distribuição e circulação de conteúdos tradicionalmente instituídos e a sua reconfiguração a partir de um cenário em que "as três formas de 
comunicação (interpessoal, comunicação de massa, e mass self-communication ${ }^{7}$ ) coexistem, interagem e que tanto complementam-se mutuamente quanto se substituem." (CASTELLS, 2009, p. 55).

É nesse cenário que emerge a narrativa transmídia que, conforme resumem Lopes e Mungioli:

Trata-se da criação de um universo ficcional cujo conteúdo pode ser expandido tanto em termos de personagens quanto em termos de desenvolvimento narrativo. Não se trata de uma repetição da história, mas de um desdobramento da história principal que ganha elementos diferentes (personagens, ambientes, conflitos) que tiram proveito das qualidades que cada um dos meios pode oferecer para o desenvolvimento da narrativa. (LOPES; MUNGIOLI, 2011, p. 253).

Entre os novos modelos de distribuição e consumo audiovisual nas redes, o grande destaque é o streaming, que funciona a partir da transmissão dos dados audiovisuais, que não podem ser gravados (oficialmente), mas visualizados online a qualquer hora e em várias plataformas (computador, tablet, celular, videogame etc). A lógica streaming vem justamente fazer oposição ao broadcast, ou seja, à grade de programação. É a partir desse paradigma que novos formatos de entretenimento se desenvolvem, realizadas muitas vezes pelas produtoras independentes fortalecidas pela Lei 12.485 .

O consumo de produtos audiovisuais em streaming transforma não só os hábitos da audiência, mas também os modelos de produção das obras. Elas são adaptadas a novas estéticas - que se referem principalmente ao tempo, fotografia e enquadramentos - para que circulem nas redes. Sem dúvida, o maior expoente dessa "nova geração" audiovisual é o YouTube, plataforma escolhida para servir como repositório da maior parte dos conteúdos audiovisuais gerados para circulação na internet.

O YouTube, por sua vez, opera sob uma lógica baseada na gratuidade. Ou seja, permite um fluxo extraordinário de conteúdos sem que o usuário pague diretamente por isso. Desse modo, a repercussão, a distribuição e a reprodução dos arquivos digitais disponibilizados nessa plataforma acontecem livremente, de maneira que as produtoras interessadas em disponibilizar seus títulos ali devem buscar padrões alternativos de

\footnotetext{
7 Castells (2009, p. 55) conceitua mass self-communication como "uma nova forma de comunicação que emergiu, caracterizada pela capacidade de mandar mensagens de muitos para muitos, em tempo real ou em determinado tempo, e com a possibilidade de comunicação ponto a ponto, narrowcasting (comunicação segmentada) ou broadcasting, dependendo da proposta ou das características de uma determinada prática de comunicação."
} 
financiamento, captação de recursos ou venda de espaços comerciais.

Outra característica do YouTube é o que se denomina "escalabilidade de redes", conceito cuja essência designa que quanto maior o número de usuários em uma rede, maior também é o seu valor. Esse teorema é análogo às medições das audiências tradicionais da TV, visto que atribui valor à plataforma de acordo com o seus índices de alcance e penetração. No caso das redes virtuais, quanto mais pessoas conectadas em determinado canal do YouTube ou mais visualizações em um vídeo viralizado, mais recursos são atraídos (na forma de publicidade), o que aumenta a possibilidade de investimentos para cooptar mais usuários e assim sucessivamente.

(...) são questões que persistem, ao mesmo tempo, o conceito de TV broadcast, está sendo alterado pelos dispositivos móveis e os hábitos do consumidor com a introdução das novas tecnologias da comunicação e da informação. Já as mídias tradicionais como a televisão e o cinema passam por um processo de redimensionamento de suas funções e modelos de negócios bem como da produção de novos formatos e gêneros em seus conteúdos e na sua difusão. (AFFINI, 2008, ps. 7 e 8).

Desse modo, é possível perceber novos formatos estabelecidos na produção, distribuição e consumo de entretenimento audiovisual a partir do cenário midiático convergente. O estímulo causado pela lei do cabo catalisou esse processo no Brasil e deu ferramentas para que os produtores criativos e independentes passassem a explorar esse novo universo de possibilidades. A partir desse ponto, serão trazidos elementos para análise do crescimento e sucesso de produções de entretenimento realizadas de maneira independente desde o início da vigência da Lei 12.485 .

\section{WEBSÉRIES: PRODUÇÕES FICCIONAIS INDEPENDENTES PARA A INTERNET}

As novas tecnologias difundidas a partir da internet moldam modos distintos de produção de entretenimento que circulam entre as mídias ditas tradicionais e estão cada vez mais ligadas a múltiplos dispositivos. "O que a Internet faz é processar a virtualidade e transformá-la em nossa realidade, constituindo a sociedade em rede, que é a sociedade em que vivemos" (CASTELLS, 2003, p. 287). Esse fenômeno explica a transposição de narrativas seriadas tradicionais da televisão para as telas de computadores, tablets e celulares. É preciso, portanto, “(...) abandonar o telecentrismo e manter um olho observando a evolução de outros 
nichos próximos à televisão, como, por exemplo, os jogos, as interfaces web e os dispositivos móveis" (SCOLARI, 2014, p. 47).

Nesse cenário, surgem as webséries, narrativas fragmentadas em webisódios que são disponibilizados em plataformas online, como blogs, tumblr, vimeo, ou YouTube. Com tempo distinto em relação aos episódios de séries televisionadas, os webisódios são geralmente mais curtos e menos comprometidos com o cronômetro: devido à inserção fora da lógica de anúncios publicitários tradicionais e da grade horária de programação, sua duração costuma ser mais flexível. Também é válido ressaltar que são realizações desenvolvidas geralmente por profissionais com experiência na área audiovisual e transmitidas com periodicidade determinada - geralmente semanal. As temáticas desenvolvidas são variadas, assim como os gêneros, cujas tramas determinam a aglomeração de comunidades virtuais ao redor das produções (Booth, 2010), o que marca a experiência online de fruição de conteúdos.

Com crescente inserção no mercado de mídias brasileiro, as webséries são contempladas com editais específicos para sua realização, e compõem a economia criativa nacional, que acumula expansão de $70 \%$ nos últimos dez $\operatorname{anos}^{8}$ e em 2014 foi responsável por $2,7 \%$ do PIB brasileiro 9 . Nesse cenário, o formato se desenvolve como mais uma possibilidade de experimentação audiovisual, que pode lograr de qualidade técnica e artística.

A aparição de novas espécies no ecossistema midiático, tais como jogos de vídeo ou a web, estão mudando o ambiente, obrigando as velhas espécies (televisão, imprensa, rádio etc.) a adaptar-se para sobreviver. Por outro lado, estamos testemunhando o nascimento de espécies bastardas, ou seja, meios híbridos que adotam ou simulam gramáticas e narrativas de outros meios. (SCOLARI, 2014, p. 49).

Sob esse entendimento de Scolari, vários produtos considerados adiante, nas análises desse trabalho, se configuram como "obras bastardas", que desvendam os novos caminhos da produção audiovisual ficcional brasileira, associando gramáticas e narrativas televisuais ao YouTube e dialogando nos processos de trocas e complementações entre as plataformas tradicionais e as mídias digitais. Quando se fala sobre o trânsito de conteúdos entre televisão e internet, cabe pontuar que o formato websérie já se configura como uma estratégia de expansão narrativa que vem se popularizando entre os títulos da Rede Globo e ganhando espaço frente ao público conectado às redes. Sejam narrativas relacionadas às tramas

\footnotetext{
8"Economia criativa avança mesmo durante recessão". Fonte: O Globo. Disponível em: http://oglobo.globo.com/economia/economia-criativa-avanca-mesmo-durante-recessao-18399357

9"Economia criativa cresce e ganha força no Brasil". Fonte: Brasil Econômico. Disponível em:

http://brasileconomico.ig.com.br/negocios/cinema-corrente/2014-11-28/economia-criativa-cresce-e-ganha-forca-nobrasil.html
} 
televisionadas ou "independentes", são novos conteúdos disponibilizados exclusivamente na $w e b$, que refletem modelos distintos de interação com as audiências e de consumo das produções ficcionais.

Na página oficial de entretenimento da emissora ${ }^{10}$, o GShow, apareciam 37 webséries disponíveis para visualização em julho de 2016. Entre elas, extensões narrativas da programação televisionada, como o Lembranças do Irajá, que se refere ao bairro onde se passa a série Pé na Cova, o Dupla Identidade.doc, que traz a construção das personagens da série Dupla Identidade, o Verdades Secretas.doc, que, analogamente, remete à trama da série Verdades Secretas, os Causos do Zé Coveiro, da minissérie Amorteamo, Os Desatinados, desdobramento online da soap opera Malhação, entre vários outros.

Tais produções objetivam criar um sistema de retroalimentação o qual, nas redes, estimula que as audiências recorram aos televisores para acessar as tramas apresentadas e, a partir da televisão, vão ao site oficial da emissora para acompanhar extensões dos conteúdos exibidos. Ou seja, não são apenas as produtoras independentes que compreenderam a necessidade de diálogo com os públicos online. É o que reitera Orozco (2014, p. 103): “[...] temos uma TV em transição, que está deixando de ser uma tela dominante para ser uma tela a mais entre muitas outras que, rotineiramente, atingem amplos setores da audiência”.

Para que pudéssemos observar a relação entre o aumento da produção ficcional brasileira desde 2011, ano da implementação da Lei da TV paga, e as webséries independentes, buscamos as séries de TV por assinatura que constituem adaptações ou continuações de webséries. O método de coleta teve como base as listas de ficções na TV paga publicadas nos Anuários OBITEL de Ficção Televisiva de 2011 a 2016. A partir dessa base de dados, encontramos sete séries ficcionais brasileiras exibidas na TV paga que teriam narrativas originadas na internet. São elas:

Quadro 1 - Ficções da TV Paga lançadas como webséries.

\begin{tabular}{|c|l|l|}
\hline Ano & Título & Canal \\
\hline \multirow{3}{*}{2011} & Adorável Psicose & Multishow \\
\cline { 2 - 3 } & Desenrola Aí & Multishow \\
\cline { 2 - 3 } & Olívias na TV & Multishow \\
\hline
\end{tabular}

${ }^{10}$ Disponível em: http://gshow.globo.com/webseries/. Acesso em julho de 2016. 


\begin{tabular}{|l|l|l|}
\multirow{2}{*}{2012} & Os Buchas & Multishow \\
\cline { 2 - 3 } & Quero ser Solteira & Multishow \\
\hline $\mathbf{2 0 1 3}$ & Latitudes & TNT \\
\hline $\mathbf{2 0 1 5}$ & Desconectados & Sony \\
\hline
\end{tabular}

Fonte: Anuários OBITEL de Ficção Televisiva de 2011 a 2016.

Campeão de produções para a TV baseadas em webséries, o canal Multishow estreou em 2011 três séries derivadas de conteúdos desenvolvidos para a internet: Adorável Psicose, Desenrola Aí e Olívias na TV. A primeira, Adorável Psicose, foi uma série de ficção sobre as situações vividas por Natalia, uma jovem escritora que decide fazer análise para tentar controlar seu comportamento obsessivo e resolver suas questões com os homens. Os dois primeiros episódios foram produzidos para veiculação no blog homônimo, desenvolvido por Natalia Klein. O projeto de Natália Klein foi apresentado de maneira experimental para conclusão do curso de Comunicação Social pela Universidade Federal do Rio de Janeiro, no qual ela afirmou que Adorável Psicose tratava-se de "uma série para internet cuja primeira temporada prevê a gravação de oito episódios com duração média de cinco minutos cada. A série [...] se destina a veiculação na internet, ainda que não se limite somente a esse espaço.” (VIANA; KLEIN, 2009). De fato, não se limitou. Entre 2010 e 2013, o Multishow, canal de TV por assinatura da Globo, exibiu a série, que chegou à sua $5^{a}$ temporada, dirigida por Guga Chermont e produzida pela Goritzia Film e, mais tarde, pela Hungry Man.

No mesmo ano, o Multishow exibiu a série Desenrola Aí, também fruto da internet. Entre 2009 e 2010, a websérie Desenrola, da Raccord Produções em parceria com o Oi Futuro, lançou 20 webisódios no Youtube. A trama infanto-juvenil retrata as típicas roubadas adolescentes de dois amigos, Boca e Amaral, e buscou satisfazer as tendências de consumo transmídia desse público. Além de websérie e série na TV paga disponível para celular, Rosane Svartman dirigiu o filme Desenrola, lançado em 2011, levando a narrativa a alcançar ainda mais telas do universo multimídia.

O terceiro título exibido pelo canal pago foi Olívias na $T V$, uma série de esquetes em quatro temporadas, de 2011 a 2013, produzida pelo próprio Multishow. A versão televisionada da produção teve origem na websérie As Olívias, que estreou no YouTube em 2009. Após o encerramento das temporadas na TV paga, as atrizes migraram para a TV aberta com As Olivias +, um quadro de esquetes de humor no programa do Roberto Justus, na 
Record. A circulação da série ultrapassa a parelha internet-TV paga e chega à TV aberta, que apesar de não ter cota obrigatória, sempre se apoiou em programação nacional. O fato indica que, mesmo que indiretamente, também as TVs abertas se beneficiam do estímulo à produção de novas narrativas brasileiras.

Em 2012, o Multishow produziu, em parceria com a produtora independente Raccord, uma versão televisiva da websérie Quero Ser Solteira ${ }^{11}$, que estreou no YouTube em junho de 2011. A trama conta a história de uma mulher que sai da casa de sua família no interior para cursar a faculdade de moda na capital do Rio de Janeiro. No mesmo ano, o canal levou ao ar Os Buchas, que estava presente na internet pelo canal Oi desde 2009. Com roteiro de Álvaro Campos e direção de Pedro Antônio Paes, mostra os dramas do universo masculino com muitas referências da cultura popular, tendo como integrante Gregório Duvivier, famoso por sua atuação nas esquetes de Porta dos Fundos, provavelmente a websérie mais famosa do Brasil.

Já com outra lógica de produção e distribuição, o projeto transmídia Latitudes assume caráter de experimentação no cenário audiovisual de entretenimento brasileiro. O que percebemos entre a maior parte dos títulos mencionados no Quadro 1 é a adaptação ou veiculação na TV de obras originalmente lançadas na internet. No caso de Latitudes, trata-se de uma produção transmídia desde a origem, concebida para circular no YouTube, televisão e também no circuito de cinemas. Desse modo, a websérie Latitudes foi ao ar concomitantemente à série televisiva, com algumas alterações na edição do produto final. A obra entra em nossa lista, desse modo, por se apresentar como uma série televisiva exibida na TV paga, cumprindo as determinações legais da lei do cabo, e também por circular no formato websérie no YouTube.

A Sony também investiu na veiculação de conteúdos originalmente realizados no formato websérie, com Desconectados, exibida em 2015, cuja trama gira em torno de estudantes de artes adultos. Com origem em uma websérie homônima, produzida em 2012 pela Cubo Filmes, a obra entra no rol de conteúdos em trânsito entre plataformas online e analógicas. Novamente, observamos uma realização para a internet ajudando emissoras da TV paga a preencherem as demandas legais estabelecidas pela lei do cabo.

Essa linha de preenchimento das cotas independentes domésticas por webséries ou conteúdos gerados para a internet mostra a relação entre o formato e a lei do cabo. Fazer uma boa produção para o YouTube pode render frutos como a venda do título para canais pagos

\footnotetext{
${ }^{11}$ Canal no YouTube: https://www.youtube.com/user/QSSwebserie. Acesso em julho de 2016.
} 
(ou mesmo canais abertos) que precisam de realizações brasileiras. Desse modo, a hipótese lançada no início do trabalho começa a se revelar verdadeira. A lei do cabo, por mais que não contemplasse normativamente os conteúdos online, estimula a sua produção por meio do fortalecimento (e mesmo por possibilitar a criação) de produtoras independentes Brasil afora. É uma adaptação necessária na indústria criativa nacional, que precisa ocupar os espaços requeridos pelas mídias digitais, cujo mercado consumidor é crescente e ávido por conteúdos.

As potencialidades desse diálogo já são, inclusive, reconhecidas em importantes premiações internacionais. O próprio Emmy Awards conta com um braço digital para dar reconhecimento às ações online de maior sucesso no mercado do entretenimento (o Digital Emmy Awards). Recentemente, em 2013, duas webséries produzidas de maneira independente pela Guerrilha Filmes e pela Cinemarketing Filmes foram agraciadas com prêmios no $L A W e b$ Series Festival, que reuniu mais de 300 produções de vários lugares do mundo em Los Angeles, EUA. Os títulos são, respectivamente, ApocalipZe ${ }^{\mathbf{1 2}}$ e Heróis ${ }^{\mathbf{1 3}}$, que ganharam na direção de fotografia, montagem de som, produção, direção, entre outras categorias.

São elementos de reconhecimento das webséries brasileiras em âmbito internacional que surgiram durante o período de implementação da lei do cabo e, portanto, merecem destaque para a análise apresentada. Essas premiações, além de apontarem produções interessantes para públicos e pesquisadores da área acompanharem de perto, servem como um termômetro das realizações que vêm sendo desenvolvidas. Ter obras nacionais entre os vencedores do maior festival de webséries do mundo indica a ascensão do mercado no Brasil.

Os festivais são ponto importante que indicam o aquecimento da produção de webséries no país. Em novembro de 2015, o Brasil sediou seu $1^{\circ}$ Festival Internacional de Webséries: o Rio WebFest, no Rio de Janeiro. Entre palestras, premiações e exibição de webisódios selecionados, a programação contou com participantes de vários países, como Canadá, EUA e Coreia do Sul - além do Brasil, é claro. A segunda edição do Rio WebFest, como ficou conhecido o evento, ocorreu em dezembro de 2016 e a terceira está prevista para dezembro de 2017. Novamente, esse evento traz elementos para considerar o crescimento e popularização do formato no mercado midiático nacional - mais uma vez, durante os anos de implementação e vigência da Lei 12.485. À medida que são realizados festivais que legitimam as webséries, o diálogo com outras plataformas e a hibridação dos formatos é insofreável.

\footnotetext{
${ }^{12}$ Canal no YouTube: https://www.youtube.com/user/webseriados. Acesso em julho de 2016.

${ }^{13}$ Canal no YouTube: https://www.youtube.com/user/Cinemarketing. Acesso em julho de 2016.
} 
Prova disso são exemplos para além das séries incluídas na nossa metodologia. Afora as séries de TV baseadas em narrativas originadas na internet, outros exemplos de ficções apontam o diálogo entre ficção, produção independente e internet. É o caso da série 3\%, primeira produção brasileira da Netflix, sob a batuta da Boutique Filmes. A obra é uma versão estendida e encarecida da websérie $3 \%{ }^{14}$, dividida em três webisódios lançados no YouTube em 2011 - lembrando: ano de implementação da lei do cabo. Também produzida pela Boutique Filmes, que é associada à ABPI-TV, a trama distópica conta a história de um mundo pós-apocalíptico onde, ao completar vinte anos, os cidadãos passam por uma série de testes que garantem a 3\% deles o acesso a um lugar com possibilidades melhores de sobrevivência. A qualidade técnica da versão de 2011 impressiona e o roteiro bem elaborado chamou atenção não apenas de público e crítica de webséries mas, recentemente, também de grandes veículos de mídia, devido também ao seu alto índice de alcance, já que o webisódio piloto teve mais de 600 mil visualizações. Desse modo, é evidente que a repercussão e sucesso de uma websérie produzida em 2011 foram notáveis a ponto de suscitarem a criação de uma série original realizada pelo maior provedor de filmes e séries do mundo. A produção para o YouTube serviu, desse modo, para fortalecer a geração de conteúdos de seus realizadores.

Não é possível deixar de falar também sobre um processo parecido, que envolve conteúdos criados para o YouTube e a televisão: O Porta dos Fundos. Composto por esquetes de humor sobre o cotidiano, é o segundo canal brasileiro no YouTube com maior número de inscritos (seguidores), mais de 11 milhões ${ }^{15}$. Em novembro de 2015, o Porta, como é conhecido informalmente, chegou à marca de 2 bilhões de visualizações somadas de todos os seus vídeos; também nesse período, ganhou o prêmio Play de Diamante, maior honraria concedida pelo YouTube aos produtores de conteúdos. Seu reconhecimento já ultrapassou as fronteiras nacionais: mundialmente, é o $5^{\circ}$ canal com mais inscritos na categoria comédia e o $18^{\circ}$ com mais inscritos em geral.

Apesar do formato dos vídeos em esquetes, falar sobre o Porta dos Fundos é pertinente porque o canal produziu algumas webséries, como Refém $^{16}$ e Viral $^{17}$, que fizeram muito sucesso - os webisódios mais acessados têm mais de 3,5 milhões e 4 milhões de views no

\footnotetext{
${ }^{14}$ Canal no YouTube: https://www.youtube.com/user/serie3porcento. Acesso em julho de 2016.

15 O número de inscritos em 23 de março de 2016 é 11.482.187, de acordo com a página oficial do grupo no YouTube (https://www.youtube.com/user/portadosfundos).

${ }^{16}$ Canal no YouTube: https://www.youtube.com/user/portadosfundos. Acesso em julho de 2016.

${ }^{17}$ Canal no YouTube: https://www.youtube.com/user/portadosfundos. Acesso em julho de 2016.
} 
YouTube, respectivamente. Devido aos impressionantes números de assinaturas e visualizações, a equipe começou a ser sondada por emissoras de televisão. Houve muita resistência sob o argumento de possivelmente perderem a liberdade de tratar qualquer assunto, que é garantida na internet. Não por acaso, a página da plataforma fala com muito poucas restrições sobre religião, política, preconceitos e outros temas espinhosos para mídia tradicional brasileira. Ainda assim, em outubro de 2014, o Porta estreia na FOX, canal a cabo, que buscava produções nacionais para preencher as cotas de horários com conteúdos nacionais, conforme demanda da lei do cabo. Esse é mais um movimento interessante que relaciona as webséries à implementação da Lei 12.485: além de darem visibilidade às produtoras e surgirem como produções colaterais de políticas de fomento à realização independente no Brasil, elas também podem ser responsáveis por ocupar os espaços destinados às produções independentes pela lei do cabo. É exatamente o caso do Porta dos Fundos, cuja produtora homônima é associada à ABPI-TV, tendo, portanto, sua produção classificada como independente e componente da grade do canal pago FOX.

A produtora inclusive fez uma nova experimentação recentemente, disponibilizando no YouTube um conteúdo originalmente transmitido pela TV paga. O Grande Gonzalez foi ao ar em novembro de 2015 pela FOX e posteriormente, já em fevereiro de 2016, os dez episódios da série ficaram disponíveis no YouTube. Apesar de essas características não serem suficientes para inserirmos o caso na análise formal dessa pesquisa, achamos importante destacar essa dinâmica que novamente confirma a aproximação dos formatos websérie e série televisiva e intensificação do trânsito de conteúdos entre ambos.

Outra produção que ficou fora do quadro desenvolvido para nossas análises foi Apocalipze, vencedora do LA Web Series Festival em 2013, conforme mencionado anteriormente. Apesar de ter sido exibida pela BBC posteriormente nesse mesmo ano, ela não consta nas listas dos anuários OBITEL, e não foi considerada em respeito à metodologia adotada para o desenvolvimento dessa pesquisa. Apesar disso, achamos relevante mencioná-la como mais uma obra que circula entre internet e televisão, como as outras destacadas acima.

Fora do universo ficcional, a história se repete, com realizações de sucesso no YouTube - como o Manual do Mundo, Miolos Fritos e Rainha da Cocada - sendo compradas por emissoras de TV paga para o cumprimento das cotas da lei do cabo. São maneiras identificadas de influências colaterais da Lei 12.485, que, ao normatizar cotas de tela para a TV paga, acabou estimulando a criação de novas produtoras independentes e fortalecendo as existentes. Esse processo não ficou restrito à televisão, mas teve repercussões também nas 
produções para a internet, como vimos a partir das webséries, que tiveram um boom em 2011 (ano em que a lei do cabo começou a vigorar) e se solidificam como formato artística e tecnicamente legítimo no ecossistema de produtos audiovisuais durante os anos seguintes. Legitimidade confirmada por premiações internacionais de webséries brasileiras e criação de festivais nacionais inteiros dedicados ao formato.

O YouTube enquanto plataforma de distribuição dos conteúdos passa a ser considerado como um caminho para que as realizações alcancem escalas globais e novos modelos de negócios e financiamento se desenvolvem sob a lógica streaming. Na era da convergência midiática, normatizações das grades horárias televisivas influenciam a produção de conteúdos para a internet e o trânsito de formatos e plataformas fica evidente na transposição de realizações entre as mídias no intuito de cumprimento das novas exigências legais - principalmente ao se levar em conta que, muitas vezes, os produtores independentes de televisão são os mesmos realizadores de conteúdos disponibilizados no YouTube, como as webséries por exemplo.

\section{CONSIDERAÇÕES}

A partir do desenvolvimento das análises descritas neste artigo, percebemos que nossa hipótese inicial da existência de relação entre a lei do cabo e as webséries se confirma, embora essa relação não seja abundante. Foi possível traçar relações entre o estabelecimento da Lei 12.485, ou Lei da TV paga, e o aquecimento do mercado brasileiro de produção de webséries durante o período no qual essa pesquisa se desenvolveu. Notadamente, 2011 foi o ano em que houve o maior número de "adaptações" de narrativas seriadas ficcionais originadas na internet para a televisão, justamente o ano de início de implementação da Lei do cabo no país.

Além disso, é notável o trânsito de conteúdos entre as plataformas e a centralidade que as produções para a internet vêm tomando no mercado de mídia mundial. Os números trazidos nesse artigo sobre as quantidades de visualizações de audiovisuais no YouTube e a consolidação de um roteiro de premiações nacionais e internacionais comprovam a suspeita apresentada no início da pesquisa. É notável que a maior parte dos títulos ora apresentados (tanto de conteúdos para a internet quanto para a televisão) é realizada por produtoras independentes associadas à ABPI-TV, justamente as mesmas que são contempladas pelas novas normas legais. 
Desse modo, apontamos a internet como uma fonte em potencial de conteúdos e ideias para a televisão, notando que os realizadores nesse e naquele ambiente muitas vezes coincidem. O estabelecimento de medidas protecionistas para uma plataforma ou para a outra, portanto, acaba tendo desdobramentos em ambas. Devido à efervescência do fenômeno aqui analisado, é cedo para prever tendências ou fazer afirmações categóricas, mas observamos por ora uma relação simbiótica entre webséries e séries televisivas que alcançou seu ápice em 2011 - talvez a diminuição posterior se deva ao estabelecimento das próprias webséries como formatos legítimos e reconhecidos tanto pelos produtores quanto pelas audiências. Mas isso é assunto para a próxima pesquisa.

\section{REFERÊNCIAS}

AFFINI, Letícia Passos. Conteúdo audiovisual: especificidades dos dispositivos móveis e da internet. In: Congresso Brasileiro de Ciências da Comunicação, XXI, 2008. Natal. Anais... São Paulo: Intercom, 2008.

BOOTH, Paul. Digital fandom: new media studies. Nova York: Peter Lang, 2010.

CASTELLS, Manuel. Communication power. New York: Oxford University Press, 2009.

Internet e Sociedade em Rede. In: MORAES, Denis de (org.) Por uma outra comunicação. Rio de Janeiro: Record, 2003

JENKINS, Henry. Cultura da Convergência. São Paulo: Aleph, 2008.

LOPES, Maria Immacolata Vassallo et al. Brasil: tempo de séries brasileiras? In: LOPES, Maria Immacolata Vassallo; OROZCO, Guillermo. (orgs). Relações de Gênero na Ficção Televisiva. Anuário OBITEL 2015. Porto Alegre: Ed. Sulina, 2015.

Brasil: Trânsito de formas e conteúdos na ficção televisiva. In LOPES, Maria Immacolata Vassallo; OROZCO, Guillermo. (orgs). Estratégias de Produção Transmídia na Ficção Televisiva. Anuário OBITEL 2014. Porto Alegre: Ed. Sulina, 2014.

Brasil: a telenovela como fenômeno midiático. In: LOPES, Maria Immacolata Vassallo; OROZCO, Guillermo. (orgs). Memória Social e Ficção Televisiva em Países Ibero-americanos. Anuário OBITEL 2013. Porto Alegre: Ed. Sulina, 2013.

Brasil: a "nova classe média" e as redes sociais potencializam a ficção televisiva. In: LOPES, Maria Immacolata Vassallo; OROZCO, Guillermo (orgs) Transnacionalização da Ficção Televisiva nos Países Ibero-americanos. Anuário OBITEL 2012. Porto Alegre: Ed. Sulina, 2012.

Brasil: caminhos da ficção entre velhos e novos meios. In: LOPES, Maria Immacolata Vassallo; OROZCO, Guillermo. (orgs). Qualidade na ficção televisiva e participação transmidiática das audiências. Anuário OBITEL 2011. Porto Alegre: Ed. Sulina, 2011.

LOPES, Maria Immacolata Vassallo; MUNGIOLI, Maria Cristina Palma. Ficção televisiva 
transmidiática: temáticas sociais em redes sociais e comunidades virtuais de fãs. In LOPES, Maria Immacolata Vassallo (Org.) Ficção televisiva transmidiática no Brasil: plataformas, convergência e comunidades virtuais. Porto Alegre: Ed. Sulina, 2011.

LOPES, Maria Immacolata Vassallo. Telenovela brasileira: uma narrativa sobre a nação.

Comunicação e Educação. São Paulo, ps. 17-34, 2003.

MATTAR, Fauze Najib. Pesquisa de marketing. Ed. Atlas. 1996.

OROZCO, Guillermo. Televisão: causa e efeito de si mesma. In: FECHINE, Y \& CARLÓN, M (orgs). O Fim da Televisão. Rio de Janeiro: Confraria do Vento, 2014.

SCOLARI, Carlos A. This is The End: as intermináveis discussões sobre o fim da televisão. In: FECHINE, Yvana \& CARLÓN, M (orgs). Fim da Televisão. Rio de Janeiro: Confraria do Vento, 2014.

SOUSA, Ana Paula da Silva e. Lei da TV paga: até que ponto a restrição a produtos estrangeiros estimula a produção local. In: V Seminário Internacional - Políticas Culturais - Setor de Políticas Culturais Fundação Casa de Rui Barbosa, Rio de Janeiro, 2014.

VIANA, Juliana Bach; KLEIN, Natália. Adorável Psicose: série de ficção baseada nas crônicas do blog homônimo e destinada à veiculação na internet. Relatório de Projeto Experimental, UFRJ, 2009

Original recebido em: 31 de janeiro de 2017

Aceito para publicação em: 20 de setembro de 2017

Clarice Greco

Professora do Programa de Pós-graduação em Comunicação da Universidade Paulista (UNIP). Pós-doutoranda na Escola de Comunicações e Artes da Universidade de São Paulo (ECA-USP), doutora e mestre pela mesma Instituição. Pesquisadora do Centro de Estudos de Telenovela da ECA-USP (CETVN) e do Observatório Ibero-americano de Ficção Televisiva OBITEL. Vice-coordenadora do grupo Obitel Brasil- USP. São Paulo, SP. claricegreco@gmail.com Doutorando no Programa de Pós-graduação em Ciências da Comunicação na Escola e Comunicações e Artes da Universidade de São Paulo (ECA-USP). Mestre pela mesma instituição. Pesquisador do Grupo de Estudos Linguagens e Discursos nos Meios de Comunicação (GELiDis). São Paulo, SP. tomazpenner@gmail.com

Esta obra está licenciada sob uma Licença Creative Commons. 